\title{
Large adnexal mass: is laparoscopic surgery a safe option?
}

\author{
Prathap Talwar, Karishma Talwar*, Pranidha Shree C. A.
}

Department of Obstetrics and Gynecology, JSS Academy of Higher Education and Research, Mysuru, Karnataka, India

Received: 29 August 2018

Accepted: 13 March 2019

\section{*Correspondence:}

Dr. Karishma Talwar,

E-mail: karishma_talwar_s@yahoo.com

Copyright: (c) the author(s), publisher and licensee Medip Academy. This is an open-access article distributed under the terms of the Creative Commons Attribution Non-Commercial License, which permits unrestricted non-commercial use, distribution, and reproduction in any medium, provided the original work is properly cited.

\begin{abstract}
Background: Laparoscopic surgery is regarded as the gold standard for management of adnexal tumours due to many advantages. Currently, the exact size of the adnexal tumour contraindicating laparoscopic management has not been clearly defined. Some studies suggest laparotomy for the treatment of adnexal tumours larger than 8 to $10 \mathrm{~cm}$. Risk of malignancy increases with large cysts. Issues with operation of huge adnexal masses are limited surgical field, difficulty in inserting trocars and removing the specimen without rupture. This study aims to evaluate the feasibility and surgical outcomes of laparoscopic surgery for large adnexal masses.

Methods: A prospective observational study was conducted in the Department of Obstetrics and Gynaecology, JSS Medical College, Mysuru.

Results: 35 patients with large adnexal masses, which were thought to be benign, were subjected to laparoscopic surgery. Mean diameter of masses as per the pre-operative ultrasound measurements was $12.2 \mathrm{~cm}$ (range: 10.1 $20.4 \mathrm{~cm}$ ). The mean operative time was 51.15 minutes, estimated blood loss was $85.4 \mathrm{ml}$, duration of postoperative hospital stay was 2.8 days. Serous cystadenoma was the most common histopathological finding. However, one case of borderline tumour was found.

Conclusions: The potential risk of malignancy is the most important limiting factor for laparoscopic management of large ovarian cysts. Therefore, it is necessary to establish risk profiles of patients with adnexal masses in order to benefit from minimally invasive surgery wherever possible. The current study supports laparoscopic management of large ovarian cysts as a technically feasible method if proper case selection is made.
\end{abstract}

Keywords: Adnexal masses, Adnexectomy, Cystectomy, Laparoscopy

\section{INTRODUCTION}

Adnexal tumours comprise of ovarian cysts, paratubal cysts and tubal pathology. It is one of the most common problems encountered in gynaecology and generally occurs during reproductive years. Laparoscopic management is considered as the gold standard management of adnexal tumours in recent times. ${ }^{1}$ The reported advantages of laparoscopic treatment include faster recovery, shorter hospital stay, decreased analgesic requirement, fewer perioperative complications and improved quality of life along with cosmetic benefit. ${ }^{2}$

However, the size of the adnexal mass is an important limitation of laparoscopic management. Traditionally, large ovarian cysts have been managed by laparotomy. ${ }^{1,2}$ Currently, the precise contraindication with reference to the size of the adnexal tumour for laparoscopic management is not clearly established. Some studies like that of Canis et al and Chapron et al, suggest that proper 
management for adnexal tumours larger than 8 to $10 \mathrm{~cm}$ in size is laparotomy. ${ }^{1,3}$ Large adnexal tumours have increased risk of malignancy. Furthermore, with respect to laparoscopic surgeries, huge adnexal masses are associated with operative difficulties such as limited surgical field, difficulty in inserting trocars and removing the specimen without rupture or spreading of cystic fluid into abdominal cavity.

This study was done to evaluate the feasibility and surgical outcomes of laparoscopic surgery for large adnexal masses.

\section{METHODS}

This was a prospective study conducted in the department of Obstetrics and Gynaecology in JSS Hospital, Mysuru, from August 2015 to September 2017. 35 patients with large adnexal masses $(>10 \mathrm{~cm})$, with features suggestive of benign disease were included.

\section{Inclusion criteria}

- Patients with large adnexal mass, which were considered to be benign by preoperative assessment, with sonographic measurement of $10 \mathrm{~cm}$ or more, were included in the study.

\section{Exclusion criteria}

- Any features doubtful for malignancy, such as thick irregular septations, presence of solid areas, ascites, and presence of internal or external excrescences on ultrasonographic examination were excluded from the study.

For all patients, clinical history pertaining to their symptoms was taken and a thorough clinical exam was done. Selected patients with suspicious features on abdominopelvic ultrasound were subjected to MRI. All patients underwent testing for CA 125, and some patients were also evaluated for other markers like alphafetoprotein, beta-human chorionic gonadotropin, and lactate dehydrogenase. Only those patients with normal tumour markers and a benign radiological picture, with a Risk Malignancy Index of less than 200 were included in the study.

Patients with known medical contraindications for laparoscopy such as compromised cardiopulmonary status or markedly increased intracranial pressure were also excluded from the study.

After preoperative work up and informed consent, patients were subjected for laparoscopic surgery. Pneumoperitoneum was created through Palmer's point. Open technique was used for large masses.

Three accessory ports were used, one being in the suprapubic area and two others being in the lower quadrants lateral to the inferior epigastric artery. The positions of these ports were altered based on the accessibility and size of the mass.

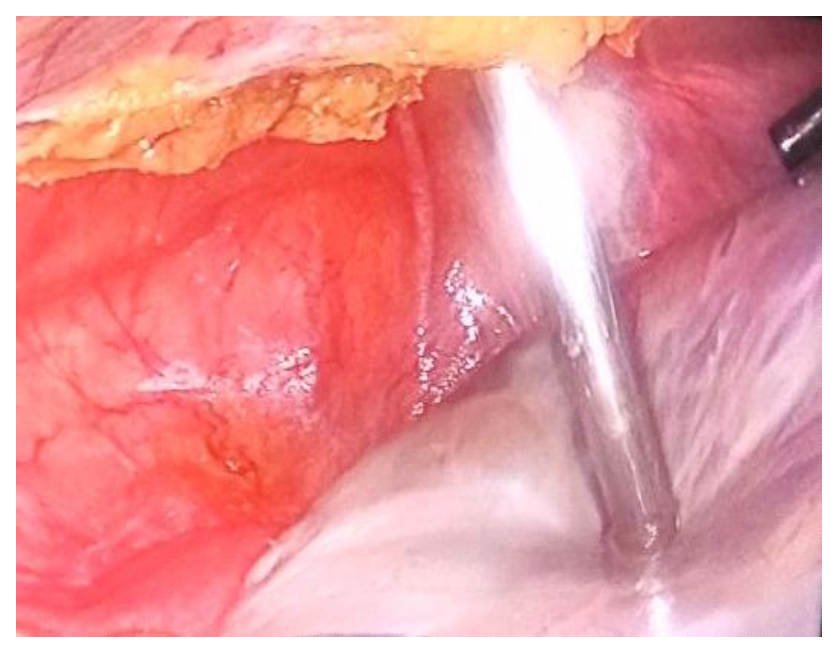

Figure 1: Large ovarian cyst.

Then an abdominopelvic inspection was done to look for omental and bowel adhesions and to confirm the preoperative diagnosis. The ovarian cyst was punctured using a secondary trocar and the cyst fluid was aspirated with the patient being kept in a reverse Trendelenburg position to prevent spillage.

Inspection of the cyst wall was done for solid areas and after that a decision was made as to whether cystectomy or adnexectomy must be performed.

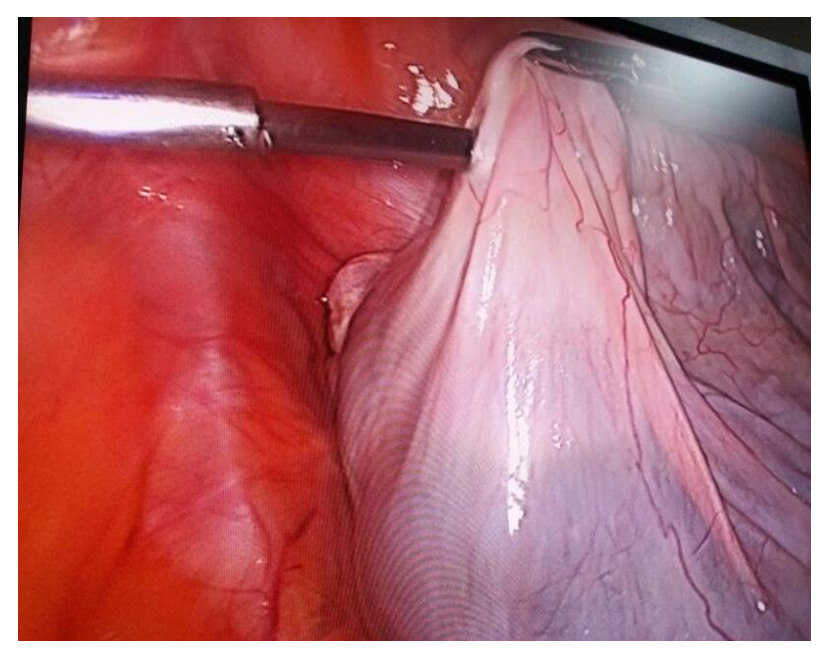

Figure 2: Large ovarian cyst being suctioned out.

In patients with endometriotic cysts, benign cystic teratomas, cysts without suspicious solid areas, and in patients who were desirous of preserving fertility, cystectomy was done.

Adnexectomy was done when the benign nature of the masses was uncertain, and the contralateral ovaries were normal. 
For dermoid cysts and suspicious cysts, a large endobag was used to avoid spillage and the specimen was removed through $10-\mathrm{mm}$ trocar site after enlarging the incision to $2-3 \mathrm{~cm}$ or by a colpotomy incision. Thereafter, the peritoneal cavity was lavaged with normal saline.

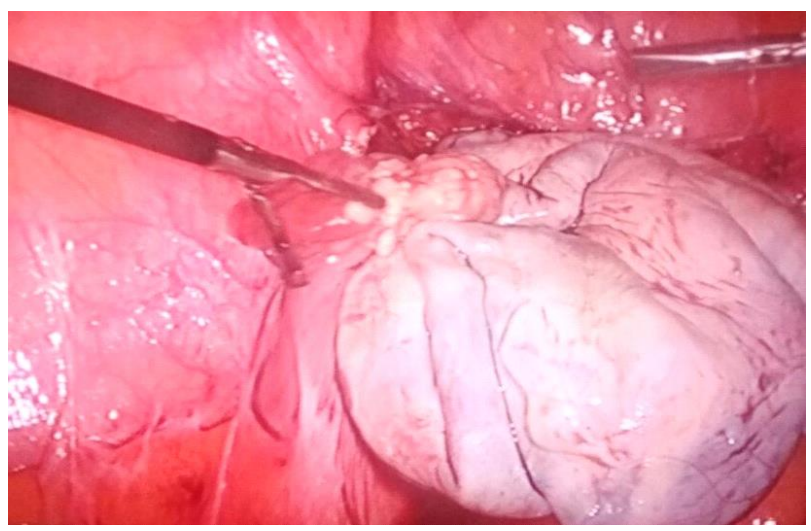

Figure 3: Shrunken cyst after being suctioned out.

Figures 1 to 5 show the approach to a large ovarian cyst. The cyst was shrunken by suctioning its contents, followed by removal through colpotomy.

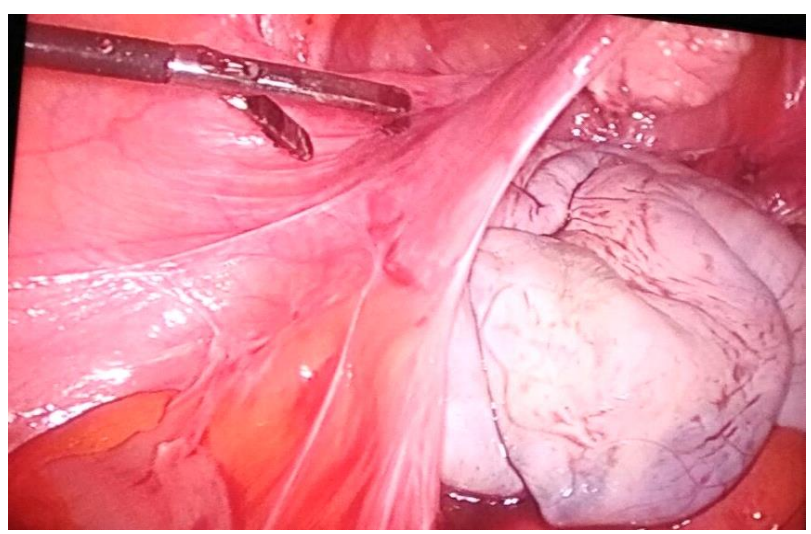

Figure 4: Specimen removal through colpotomy.

All the specimens were sent for histopathological examination and the reports were followed up.

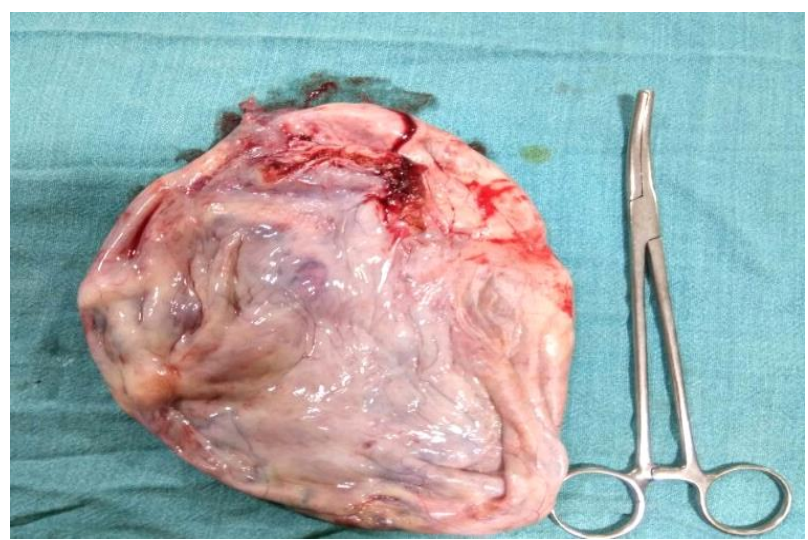

Figure 5: Specimen obtained through colpotomy.

\section{RESULTS}

In present study, 35 patients with large adnexal masses, which were thought to be benign, were subjected to laparoscopic surgery. The mean age of the patients was 32.2 years (range: $14-43$ years). Most common presenting symptom was abdominal pain $(65.7 \%)$. 9 patients were celibate, 8 were nulliparous and 18 were parous. Mean diameter of masses as per the pre-operative ultrasound measurements was $12.2 \mathrm{~cm}$ (range: $10.1-20.4 \mathrm{~cm}$ ).

Table 1: Patient details.

\begin{tabular}{|l|l|l|}
\hline Patient characteristic & Mean & Range \\
\hline Age $($ years $)$ & 32.2 & $14-43$ \\
\hline BMI $\left(\mathrm{kg} / \mathrm{m}^{2}\right)$ & 25.4 & $18.7-32.4$ \\
\hline Cyst diameter $(\mathrm{cm})$ & 12.2 & $10.1-20.4$ \\
\hline
\end{tabular}

Table 1 gives a description of patient characteristics and Table 2 shows the presenting symptoms of the patients.

Table 2: Presenting symptoms.

\begin{tabular}{|l|l|l|}
\hline Symptoms & Number & Percentage \\
\hline Pain abdomen & 23 & 65.7 \\
\hline Menstrual irregularities & 4 & 11.42 \\
\hline Dysmenorrhoea & 3 & 8.57 \\
\hline Mass per abdomen & 3 & 8.57 \\
\hline Incidental finding & 2 & 5.71 \\
\hline
\end{tabular}

All patients underwent thorough clinical examination, radiological examination and evaluation of relevant tumour markers. CA125 was done for all patients, values ranging from $5.72 \mathrm{IU} / \mathrm{ml}$ to $62.78 \mathrm{IU} / \mathrm{ml}$, with mean value being $11.7 \mathrm{IU} / \mathrm{ml}$. Risk of Malignancy Index for all patients was less than 200 .

Table 3: Intra operative parameters.

\begin{tabular}{|l|l|l|}
\hline Parameter & Mean & Range \\
\hline Operative duration (minutes) & 51.15 & $25-100$ \\
\hline Estimated blood loss (ml) & 85.4 & $40-150$ \\
\hline $\begin{array}{l}\text { Duration of post op } \\
\text { hospital stay (days) }\end{array}$ & 2.8 & $1-4$ \\
\hline \begin{tabular}{l} 
Conversion to laparotomy \\
\hline
\end{tabular} & None & None \\
\hline
\end{tabular}

The intraoperative parameters studied were duration of surgery, estimated blood loss, and duration of postoperative hospital stay, the details of which are described in Table 3. 51.15 minutes was the mean operative time. The average blood loss during surgery was $85.4 \mathrm{ml}$ and the mean post-operative hospital stay was 2.8 days. All cases were completed laparoscopically and there was no conversion to laparotomy.

The surgeries performed included ovarian cystectomy, salpingo oophorectomy and para ovarian cystectomy, the details of which are given in Table 4. 
Table 4: Type of surgery done.

\begin{tabular}{|l|l|}
\hline Surgery done & Number \\
\hline Left ovarian cystectomy & 7 \\
\hline Right ovarian cystectomy & 7 \\
\hline Left salpingoophorectomy & 6 \\
\hline Right salpingoophorectomy & 4 \\
\hline Bilateral salpingoophorectomy & 6 \\
\hline Right paraovarian cystectomy & 2 \\
\hline B/L salpingectomy & 1 \\
\hline B/L paraovarian cystectomy & 1 \\
\hline Right salpingectomy & 1 \\
\hline Total & 35 \\
\hline
\end{tabular}

There were no major intraoperative complications noted, such as major vascular injury, bowel injury or bladder injury (Table 5).

Table 5: Perioperative complications.

\begin{tabular}{|l|l|l|}
\hline Perioperative complications & Number & Percentage \\
\hline Fever & 2 & 5.7 \\
\hline Wound infection & 1 & 2.8 \\
\hline Vomiting & 3 & 8.5 \\
\hline Urinary retention & 1 & 2.8 \\
\hline Paralytic ileus & 1 & 2.8 \\
\hline Shoulder tip ache & 2 & 5.7 \\
\hline Major vascular injury & Nil & \\
\hline Bowel injury & Nil & \\
\hline Ureteric injury & Nil & \\
\hline Bladder injury & Nil & \\
\hline
\end{tabular}

Histopathological reporting was done for all patients. Most commonly found cases were serous cystadenoma and dermoid cyst. Others included mucinous cystadenoma, simple cysts, haemorrhagic ovarian cyst, endometriotic cyst and hydrosalpinx as mentioned in Table 6.

Table 6: Histopathological reports.

\begin{tabular}{|l|l|l|}
\hline Histopathological report & Number & Percentage \\
\hline Serous cystadenoma & 7 & 20 \\
\hline Dermoid cyst & 7 & 20 \\
\hline Haemorrhagic cyst & 5 & 14.3 \\
\hline Simple cyst & 4 & 11.4 \\
\hline Hydrosalpinx & 3 & 8.6 \\
\hline Mucinous cystadenoma & 3 & 8.6 \\
\hline $\begin{array}{l}\text { Bilateral haemorrhagic cyst } \\
\text { Serous cystadenofibroma }\end{array}$ & 1 & 2.8 \\
\hline Endometriotic cyst & 1 & 2.8 \\
\hline No significant pathology & 1 & 2.8 \\
\hline Fibrothecoma & 1 & 2.8 \\
\hline $\begin{array}{l}\text { Borderline serous } \\
\text { cystadenoma }\end{array}$ & 1 & 2.8 \\
\hline
\end{tabular}

One case of borderline serous cystadenoma was noted. It was a 23 year old celibate patient, who presented with abdominal pain. Clinical examination revealed a cystic mass up to 18-20 weeks gravid uterus size. Ultrasound was suggestive of a benign natured lesion and tumour markers were within normal limits. Intraoperatively, no suspicious features were noted. Patient underwent adnexectomy and was asked to follow up.

Histopathological outcomes in other similar studies are shown in Table 7.

\section{DISCUSSION}

Laparoscopic surgery is considered as the treatment of choice in the treatment of small to moderate sized adnexal masses, but experience related to laparoscopic management for large ovarian masses remains limited. ${ }^{4}$ The size $10 \mathrm{~cm}$ was used as a definition for a large ovarian cyst in the present study, similar to a study done by $\mathrm{Ou}$ CS et al. ${ }^{5,6}$ In the present study, the mean age of the patients was 32 years and range being 14 to 43years, compared to a study by Alobaid et al, in which the mean age was 30.6 years. ${ }^{2}$ The chief complaint was abdominal pain in $65.7 \%$ of patients in the current study, which was similar to a study by Eltabbakh et al, where in $69.7 \%$ patients presented with abdominal pain and Lim et al. in which $29.6 \%$ patients presented with abdominal pain. ${ }^{7,8}$

In the current study, the mean cyst size is $12.2 \mathrm{~cm}$ (range: 10.1-20.4), compared to a range of $13-14.6 \mathrm{~cm}$ as per studies done by Lim et al and Eltabbakh et al. ${ }^{7,8}$

An important factor for laparoscopic management of a large ovarian cyst is the patient's age. In young patients desiring preservation of fertility, cystectomy was done after aspiration of cyst.

Similar to the Stamatellos et al study, cyst aspiration was done in reverse Trendelenberg position in large cysts to aid their removal laparoscopically after malignancy had been excluded. ${ }^{9}$ There are serious concerns about intraperitoneal spillage and peritoneal seeding. Therefore, a thorough and copious peritoneal lavage was performed immediately after the procedure with irrigation saline. ${ }^{10}$

Adnexectomy should be considered a better option for suspicious cases, provided that the contralateral ovaries are normal. ${ }^{11}$ According to Fauvet et al, for the management of borderline malignancy laparoscopic cystectomy or adnexectomy is preferred and patient survival is not affected, although the risk of recurrence was high in that study's cystectomy group. ${ }^{12}$ Tumour recurrence and metastatic disease are rare in borderline ovarian tumors. ${ }^{13,14}$

Table 7: Histopathological picture in different studies.

\begin{tabular}{|l|l|l|}
\hline Lim et $\mathrm{al}^{11}$ & Borderline (\%) & Malignant (\%) \\
\hline Paul et $\mathrm{al}^{14}$ & 9.7 & 2.5 \\
\hline Current study & 2.8 & None \\
\hline
\end{tabular}


Conversion to laparotomy occurred in none of the patients, whereas conversion to laparotomy occurred in $4.9 \%-6.1 \%$ of patients in studies done by Eltabbakh et al and Lim et al. ${ }^{7,8}$

As per a Cochrane database system review, Medeiros et al showed the results of nine randomized controlled trials ( $\mathrm{N}=482$ women), which stated that laparoscopic surgery was associated with fewer adverse events of surgery, lesser post-operative pain, and lesser hospital stay than laparotomy. In one of the studies significant reduction in costs when compared to laparotomy was found. ${ }^{15}$

\section{CONCLUSION}

The potential risk of malignancy rather than cyst size is the limiting factor for laparoscopic management of large ovarian cysts. Hence, it is essential to establish risk profiles of all patients with adnexal masses in order to achieve the benefit of minimally invasive surgery wherever possible.

\section{Funding: No funding sources}

Conflict of interest: None declared

Ethical approval: The study was approved by the Institutional Ethics Committee

\section{REFERENCES}

1. Canis M, Rabischong B, Houlle C, Botchorishvili R, Jardon K, Safi A, et al. Laparoscopic management of adnexal masses: a gold standard? Curr Opin Obstet Gynecol. 2002;14:423-8.

2. Escobar PF, Starks D, Fader AN, Catenacci M, Falcone T. Laparoendoscopic single-site and natural orifice surgery in gynecology. Fertil Steril. 2010;94:2497-502.

3. Chapron C, Dubuisson JB, Kadoch O, CapellaAllouc S, Vacher-Lavenu MC. Laparoscopic management of organic ovarian cysts: is there a place for frozen section diagnosis? Hum Reprod. 1998;13:324-9.

4. Alobaid A, Memon A, Alobaid S, Aldakhil L. Laparoscopic management of huge ovarian cysts. Obstet Gynecol Int. 2013;2013:380854.

5. Ou CS, Liu YH, Zabriskie V, Rowbotham R. Alternate methods for laparoscopic management of adnexal masses greater than $10 \mathrm{~cm}$ in diameter. $\mathrm{J}$ Laparoendosc Adv Surg Tech A. 2001;11:125.

6. Shindolimath VV, Jyoti SG, Patil KV, Ammanagi AS. Laparoscopic management of large ovarian cysts at a rural hospital. J Gynecol Endos Surg. 2009;1:94.

7. Eltabbakh GH, Charboneau AM, Eltabbakh NG. Laparoscopic surgery for large benign ovarian cysts. Gynecol Oncol. 2008;108:72.

8. Lim S, Lee KB, Chon SJ, Park CY. Is tumor size the limiting factor in a [sic] laparoscopic management for large ovarian cysts? Arch Gynecol Obstet. 2012;286:1227.

9. Stamatellos I, Karydas C, Anagnostou E, Stamatopoulos P, Apostolidis A, Bontis I. Laparoscopic treatment of premenopausal patients with benign adnexal pathology. Gynecol Surg. 2006;3:66.

10. Gocmen A, Atak T, Ucar M, Sanlikal F. Laparoscopy-assisted cystectomy for large adnexal cysts. Arch Gynecol Obstet. 2009;279:17-22.

11. Paul PG, Chopade G, Patil S, Das T, Thomas M, Garg R. Should we manage large ovarian cysts laparoscopically? J Gynecol Surg. 2016;32(5):251-6.

12. Fauvet R, Boccara J, Dufournet C, Ponecelet C, Dara1 E. Laparoscopic management of borderline ovarian tumors: Results of a French multicenter study. Ann Oncol. 2005;16:403.

13. Chen VW, Ruiz B, Killeen JL, Coté TR, Wu XC, Correa $\mathrm{CN}$, et al. Pathology and classification of ovarian tumors. Cancer: Interdisc Int J Am Cancer Soc. 2003;97(S10):2631-42.

14. Dembo AJ, Davy M, Stenwig AE, Berle EJ, Bush RS, Kjorstad K. Prognostic factors in patients with stage I epithelial ovarian cancer. Obstet Gynecol. 1990;75:263.

15. Medeiros LR, Rosa DD, Bozzetti MC, Hachel JM, Furness S, et al. Laparoscopy versus laparotomy for benign ovarian tumour. Cochrane Database Syst Rev 2009;15:CD004751.

Cite this article as: Talwar P, Talwar K, Shree PCA. Large adnexal mass: is laparoscopic surgery a safe option? Int J Reprod Contracept Obstet Gynecol 2019;8:1431-5. 